Article

\title{
Research on the Influence of Energy Utilization and Economic Development on Human Well-Being in Qinghai-Tibet Plateau
}

\author{
Mengmeng Meng ${ }^{1}$, Weiguo Fan ${ }^{1, *}$, Jianchang Lu ${ }^{1}$, Xiaobin Dong ${ }^{2}$ and Hejie Wei ${ }^{3}(\mathbb{D}$ \\ 1 Department of Economics and Management, North China Electric Power University, Baoding 071003, China; \\ mzhjingjing@163.com (M.M.); ljcwlljcwl@163.com (J.L.) \\ 2 State Key Laboratory of Earth Surface Processes and Resource Ecology, Faculty of Geographical Science, \\ Beijing Normal University, Beijing 100875, China; xbdong@bnu.edu.cn \\ 3 College of Resources and Environmental Sciences, Henan Agricultural University, Zhengzhou 450002, China; \\ hjwei@henau.edu.cn \\ * Correspondence: fwgcnan@ncepu.edu.cn
}

Citation: Meng, M.; Fan, W.; Lu, J.; Dong, X.; Wei, H. Research on the Influence of Energy Utilization and Economic Development on Human Well-Being in Qinghai-Tibet Plateau. Sustainability 2021, 13, 196. https:// doi.org/10.3390/su13010196

Received: 11 November 2020 Accepted: 24 December 2020 Published: 28 December 2020

Publisher's Note: MDPI stays neutral with regard to jurisdictional claims in published maps and institutional affiliations.

Copyright: $\odot 2020$ by the authors. Licensee MDPI, Basel, Switzerland. This article is an open access article distributed under the terms and conditions of the Creative Commons Attribution (CC BY) license (https:/ / creativecommons.org/ licenses/by/4.0/).

\begin{abstract}
Qinghai-Tibet Plateau is a typical resource-rich but economically backward region in western China, and it is of great urgency to improve human well-being. Combined with previous scholars' research and the characteristics of Qinghai-Tibet Plateau, this paper constructs an index system of human well-being including four dimensions: income and consumption, means of production, means of subsistence, and resource acquisition ability. Then, it uses generalized matrix method estimations to measure the influence of energy utilization and economic development on human well-being and makes a regression analysis on the influence of energy utilization and economic development on human well-being in various provinces in this region. It is found that per capita GDP and coke utilization promote the well-being of all dimensions, while the urban registered unemployment rate only promotes the well-being of means of subsistence. The utilization of gasoline and natural gas promotes income and consumption and inhibits the means of subsistence and resource acquisition ability, but they have opposite effects on means of production. The impacts of energy utilization and economic development in different provinces on human well-being are different. This study is of great significance to the related research aiming at improving people's livelihood and promoting regional development.
\end{abstract}

Keywords: Qinghai-Tibet Plateau; human well-being; economic development; energy utilization; principal component analysis; dynamic panel model

\section{Introduction}

Sustainability and well-being evaluation are a contemporary theme of major scientific and policy relevance. The United Nations Sustainable Development Goals pursue a global transition to a society in which all members enjoy high human well-being without expanding the boundaries of the earth [1]. With the progress of society, more and more scholars have proposed that economic development is only a means to achieve sustainable development goals, and human well-being is its core [2]. Human well-being is an important concept of interaction between man and nature. Influenced by social, ecological, and personal factors, the public has increasingly reached a consensus on the importance of human well-being. Economic development and energy utilization are important influencing factors to achieve sustainable social development. Economic development is often accompanied by energy utilization, which not only promotes social development but also brings a series of ecological and environmental problems, which offset the improvement of human well-being to a certain extent. How to make economic development and energy utilization improve human well-being to the greatest extent, and realize the sustainable development of energy, environment, and economy has become an important issue of global academic circles and governments. 
Since the reform and opening-up, China's economy has achieved continuous and rapid growth, people's living standards in various regions have generally improved, and great achievements have been made in human development, but there has also been an imbalance in regional development. The overall development level of a country is directly affected by regional development, especially in underdeveloped regions. With the continuous evolution of the development concept, the foothold of regional development quality evaluation has gradually shifted from economic growth to people's well-being, so we must pay attention to the development of human well-being in underdeveloped regions. Qinghai-Tibet Plateau belongs to the strategic area of China's western development, and it is a special area with rich natural resources but an underdeveloped economy. At present, there is no well-being index system that can systematically reflect the economic development of Qinghai-Tibet Plateau, and there is little mention of the impact of economic development and energy utilization on human well-being. Therefore, studying the impact of energy utilization and economic development on human well-being in Qinghai-Tibet Plateau can make the region make more rational use of its advantages in resources, promote the construction of economy and infrastructure, promote the improvement of people's living standards, and ultimately improve the people's well-being in the region and even the overall well-being of the country. Therefore, this paper constructs an index system of human well-being including four dimensions: income and consumption, means of production, means of subsistence, and resource acquisition ability. Then, it uses generalized matrix method (GMM) estimation to measure the influence of energy utilization and economic development on human well-being and makes a regression analysis on the influence of energy utilization and economic development on human well-being in various provinces in this region.

\section{Literature Review}

The concept of human well-being is complex, controversial, and constantly developing. Human well-being in a broad sense includes economic well-being, health well-being, cultural well-being, and social well-being [3]. Wang et al. think that human well-being is the bridge between the natural ecosystem and human society [4]. Zang $Z$ believes that human well-being is expressed by life expectancy, education level, and gross national income [5]. Although there is no uniform definition of well-being, researchers mostly discuss the connotation of well-being from the aspects of welfare, happiness, quality of life, and life satisfaction [6]. At present, the research on the influencing factors of human wellbeing is increasing. For example, in terms of the impact of ecosystem services on human well-being, Wei took the mountainous-oasis-desert region of Xinjiang as an example and studied the relationship among ecosystem services supply, social needs, and human wellbeing. The results showed that human well-being is positively correlated with the supply of supply services, but negatively correlated with the supply of regulatory services [7]. Zhen et al. analyzed the impact of ecosystem service changes on the well-being of local farmers in Guyuan City, Ningxia. The results showed that labor opportunities, water, food, and air have the greatest influence on the well-being of local farmers [8]. With regard to the impact of economic development on human well-being, Manuel analyzed the relationship between economic growth and human development in Ecuador. The results showed that economic growth contributes to human development through government activities and civil society, and there is only a long-term relationship between economic growth and human development [9]. Similarly, Suri et al. used panel data of developing countries to discuss the two-way relationship between economic growth and human development and found that human development determines the trajectory of economic growth and the feedback effect of economic growth maintains human development [10]. Pagliari et al. studied the influence of economic growth on human well-being in the world system and found that there is a general trend of linking high-level human well-being with high-level economic growth, but due to the influence of historical conditions and socio-economic politics, this trend is not necessarily defined as causality [11]. Zhang et al. analyzed the 
quality of life of 30 provincial capitals in China and found that there is a contrast between the rapid economic growth and the improvement of residents' quality of life [12]. Hou et al. used the Driver-Pressure-State-Impact-Response (DPSIR) model to quantitatively study the impact of Jiangsu's social economy on human well-being. The results showed that industrialization, agricultural technology development, financial support, and rural education are the main positive factors affecting the well-being of rural residents [13]. Brady et al. assessed the impact of economic growth on the well-being of underdeveloped countries and concluded that there are serious limitations in focusing only on economic growth to improve the well-being of underdeveloped countries [14]. Basakha et al. used an econometric model to analyze the impact of Iran's industrial development on human well-being from 1967 to 2015. The results showed that industrial development has a positive impact on Iran's social well-being, and its long-term impact is more obvious than short-term impact [15].

In addition, scholars have studied the impact of energy utilization on human wellbeing from both direct and indirect aspects. For example, Steinberger analyzed the relationship between human demand, energy consumption, and carbon emissions by using the data of countries around the world from 1975 to 2005. The results showed that high-level human development can be achieved at moderate energy and carbon levels [16]. Martinez analyzed the correlation between the human development index and per capita energy consumption in 120 countries. The results showed that with energy consumption, human development in energy-poor countries rises sharply, while that in transition countries rises moderately, while human development in energy-dominant countries does not increase, and even there is an obvious secondary trend [17]. Schandl et al. analyzed the resource efficiency and utilization of the Asia-Pacific region and found that the Asia-Pacific region has low resource utilization efficiency, which has a certain negative impact on the well-being of the ecological environment [18]. From the perspective of urban sustainable development efficiency, Yan constructed an evaluation framework for urban sustainable development based on natural resource input and human well-being output [19]. Hao et al. used the SDM model to analyze the environmental Kuznets curve (EKC) of per capita coal consumption in 29 provinces of China from 1995 to 2012, the results showed that there was an inverted u-shaped EKC relationship between per capita coal consumption and GDP [20]. Al-mulali used the CCR model to discuss the two-way long-term relationship between energy consumption and quality of life in 198 countries. The results showed that energy consumption has improved the quality of life in $70 \%$ of countries, and the quality of life has increased the energy consumption in $65 \%$ of countries [21]. With the increase of energy consumption, the emissions of environmental pollutants such as carbon dioxide and nitrogen oxides are increasing year by year, and the impact of fossil energy on the environment and global climate is becoming increasingly serious. On a more distinct level, the study of the impact of environmental issues on human well-being has attracted more and more attention. Smyth investigated the relationship between environmental variables and subjective well-being and found that reducing air pollution can improve the well-being of Chinese cities [22]. Similarly, Ferreira et al. used econometric models to analyze the impact of air pollution on human well-being in Europe, and the results showed that air pollution had a significant negative impact on personal life satisfaction [23]. Welsch studied how subjective well-being changes with air quality and income and found that the impact of air pollution on well-being is a considerable monetary value [24]. Ferrer et al. studied the relationship between subjective well-being and personal environmental attitude and found that not all environmental problems will have a negative impact on personal well-being, and attention to positive environmental characteristics is positively related to happiness, while negative attention is the opposite [25].

In the process of studying the impact of energy utilization and economic development on human well-being, scholars from various countries mainly analyze the energy intensity of human well-being (EIWB). For example, Jorgenson et al. analyzed the impact of economic development on EIWB in 12 Central and Eastern European countries from 1992 to 2010 by 
using the bidirectional fixed effect panel model. The research showed that the relationship between EIWB and economic development is becoming more and more sustainable from 2007 to 2010 [26]. Jorgenson et al. also studied the influence of economic growth on EIWB in developed and underdeveloped countries. The results showed that economic growth has little influence on the EIWB of underdeveloped countries, but has a great influence on the EIWB of developed countries [27]. Li et al. analyzed the interdependence of economic development, environment, and human well-being in 30 provinces of China from 1995 to 2016 from the perspective of the carbon intensity of human well-being (CIWB). Studies have shown that with economic development, CIWB has an inverted $\mathrm{N}$ shape [28]. Wang added per capita carbon emission index into HDI to construct a carbon emission sensitive human well-being index (HWI) and used the LMDI method to analyze the driving effect and spatial-temporal differentiation of human well-being changes in China, regions, and provinces from 1980 to 2010. The results showed that before 2000, human well-being changes mainly depended on the two-wheel-drive of economy and technology, and after 2000, the driving effect of technological progress and the inhibition of ecological efficiency were more obvious [29]. Sweidan et al. analyzed the impact of economic development on the energy intensity of human well-being in Gulf Cooperation Council (GCC) countries. The results showed that the economic development of GCC countries is the only factor causing environmental pressure [30]. Knight et al. tested the influence of climate, political, economic, and social factors on the environmental efficiency of human well-being from the data of 105 countries in the world, and mainly found the negative secondary effect of economic development on the environmental efficiency of human well-being and the positive influence of social capital [31]. Wang et al. used the two-stage least squares (2SLS) method to analyze the relationship between renewable energy consumption, economic growth, and human development index in Pakistan from 1990 to 2014. The empirical results showed that renewable energy consumption cannot improve the human development process in Pakistan, and economic growth has a significant negative impact on the human development index [32].

Through the above literature analysis, although there is no unified definition of wellbeing, for the Qinghai-Tibet Plateau region, where economic development is backward and slow, improving its economic well-being is crucial to improving the overall well-being level of local residents. Secondly, scholars basically build mathematical models based on data to analyze the impact of single or multiple factors on human well-being. When studying the impact of energy utilization and economic development on human well-being, scholars from various countries mainly analyze the impact of economic development on human well-being from the point of view of EIWB, and seldom directly study the specific impact of energy utilization and economic development on human well-being. Therefore, this article selects the Qinghai-Tibet Plateau, which can represent underdeveloped areas, as the research object, and selects 18 sub-categories to measure human well-being, then we use principal component analysis to condense each sub-category into four-dimensional indicators: income and consumption, means of production, means of subsistence and resource acquisition ability. Finally, we use a dynamic panel model to measure the impact of energy utilization-economic development on the four dimensions of human well-being in Qinghai-Tibet Plateau, and conduct an in-depth analysis of the impact of energy utilization and economic development on human well-being in each province in the region.

\section{Methodologies and Data Sources}

\subsection{Data Collection and Sources}

The Millennium Ecosystem Assessment (MA) is authoritative in the research of the relationship between ecosystem services and human well-being, which defines the components of human well-being as five aspects: safety, basic material needs for maintaining a high quality of life, health, good social relations and freedom of choice and action [33]. In addition, domestic and foreign scholars have also discussed the connotation and index system of human well-being. For example, Wang et al. believe that human well-being is a 
bridge between natural ecosystems and human society. It is affected by society, ecology, and individuals, but personal mental health is often overlooked [34]. Sarkki agrees that human well-being includes the material basis of a good life, social relations, happiness, living in harmony with nature, freedom, mobility, self-determination, health, safety, belonging, and a sense of respect [35]. Fulford described human well-being with eight indicators: health, connection with nature, cultural achievements, education, leisure time, living standard, safety and security, and social cohesion [36]. Considering the controversial concept of well-being, Basakha et al. used Social Welfare Composite Index (SWCI) and Sen Welfare index (SEN) to evaluate Iranian social well-being [15]. Yang expressed economic wellbeing with the Engel coefficient, the average wage of on-the-job workers, and per capita disposable income [37]. On the basis of scholars' research, comprehensively considering the division of human well-being elements by the Millennium Ecosystem Assessment (MA) and the industrial structure of the Qinghai-Tibet Plateau that depend on agriculture, special resource advantages, and the availability of data, this paper constructs an index system of human well-being which is suitable for evaluating the development degree of Qinghai-Tibet Plateau from four aspects: income and consumption, means of production, means of subsistence and resource acquisition ability. Income and Consumption (IAC) is an important index to measure people's quality of life. Means of Production (MOP) is a necessary material condition for any society to carry out material production. Means of Subsistence (MOS) refers to the social products used to meet people's material and cultural needs. To a certain extent, Resource Acquisition Ability (RAA) reflects the degree of driving hardware facilities and social security in the process of economic development and is the material basis for judging that human beings maintain a high quality of life. Considering the special structure of agriculture and animal husbandry and economic development in Qinghai-Tibet Plateau, and combining with the availability of data, the index system of human well-being is constructed by selecting the indicators shown in Table 1 below. The Engel coefficient includes the Engel coefficient of urban residents (UEC) and Engel coefficient of rural residents (REC).

Table 1. Index System of Human Well-being.

\begin{tabular}{|c|c|c|}
\hline Sort & $\begin{array}{l}\text { Elements of Human } \\
\text { Well-Being }\end{array}$ & Evaluation Index-Index Abbreviation \\
\hline \multirow{6}{*}{ IAC } & Income structure & Proportion of tertiary industry-PT (\%) \\
\hline & Consumer price & Consumer Price Index-PI (\%) \\
\hline & Gross receipts & Per capita disposable income of urban residents-UR (Yuan) \\
\hline & Goss receipls & Per capita disposable income of rural residents-RH (Yuan) \\
\hline & Consumption structure & Engel coefficient-EC $(\%)$ \\
\hline & arable land & Cultivated land area per capita-CL (Ha/person) \\
\hline \multirow[t]{4}{*}{ MOP } & Agricultural machinery & Total power of agricultural machinery per unit area-AM $(\mathrm{Kw} / \mathrm{ha})$ \\
\hline & Agricultural chemistry & Agricultural film input per unit area-AF $(\mathrm{T} / \mathrm{ha})$ \\
\hline & Agricultural products & Grain possession per capita-GP (Tons/person) \\
\hline & Animal by-products & Milk possession per capita-CP (Tons/person) \\
\hline \multirow{5}{*}{ MOS } & & Per capita clothing expenditure of urban residents-UCE (Yuan) \\
\hline & Dress & Per capita clothing expenditure of rural residents-RCE (Yuan) \\
\hline & & Per capita motorcycle ownership of urban residents-UMC \\
\hline & Travel tool & (Cars/per hundred households) \\
\hline & & $\begin{array}{l}\text { Per capita motorcycle ownership of } \\
\text { rural residents-RMC (Cars/per hundred households) }\end{array}$ \\
\hline \multirow{4}{*}{ RAA } & Highway & Highway cargo turnover-CT (Million ton-km) \\
\hline & Operation & Passenger volume-PV (Ten thousand person) \\
\hline & Civil aviation & Civil aviation cargo volume-CA (Ten thousand tons) \\
\hline & Health & Number of medical and health institutions-MH \\
\hline
\end{tabular}

Per capita gross domestic product (PGDP) is an effective tool for people to understand and grasp the macro-economic operation of a country or region. As an important regulation indicator adopted by the Chinese government in formulating social and economic development plans, the registered urban unemployment rate (RU) is the only statistical indicator officially announced and accepted to reflect the scale of unemployment in China. PGDP and RU are both important indicators to measure economic development. Therefore, this paper measures economic development by PGDP and RU, and measures energy utilization by representative Coke utilization, gasoline utilization, and natural gas utilization, and 
studies the impact of energy utilization and economic development on human well-being in the Qinghai-Tibet Plateau. Taking into account the relationship between administrative divisions and economic divisions, as well as the similarity of natural geographical conditions and resource endowments and the spatial adjacency, the six administrative divisions of Qinghai, Tibet, Gansu, Yunnan, Sichuan, and Xinjiang represent the QinghaiTibet Plateau. In this paper, the data of six provinces from 2000 to 2017 were collected. The data used in this paper comes from 2000-2018 China Statistical Yearbook, Sichuan Statistical Yearbook, Yunnan Statistical Yearbook, Gansu Statistical Yearbook, Xinjiang Statistical Yearbook, Qinghai Statistical Yearbook, Tibet Statistical Yearbook, and China Energy Statistical Yearbook [38-45]. Among them, the index data of economic development and human well-being comes from the statistical yearbooks of China and Qinghai, Tibet, Gansu, Yunnan, Sichuan, and Xinjiang provinces. The original data of energy consumption comes from China Energy Statistics Yearbook. The standard coal conversion coefficient comes from the General Principles for Calculation of Comprehensive Energy Consumption. Data on energy consumption in Tibet comes from a field investigation conducted by the Tibet Autonomous Region Statistics Bureau. In order to eliminate the impact of inflation, this paper adjusts the per capita GDP, the disposable income of rural residents and urban residents, and the per capita clothing expenditure of rural residents and urban residents to constant prices in 2000 .

\subsection{Principal Component Analysis}

The principal component analysis is the study of how to explain the internal structure of multiple variables through a few principal components. That is to derive a few principal components from the original variables, so that they retain as much information about the original variables as possible, and are independent of each other. The principal component analysis is often used to find comprehensive indicators to judge things or phenomena and to interpret the information contained in the comprehensive indicators appropriately [46]. The weight of each principal component is its contribution rate, and the weight is the ratio of the variance contribution rate of the principal component to the cumulative variance contribution rate, which reflects the proportion of the information contained in the principal component to the total information, and overcomes the defect of determining the weight in other methods. Therefore, this paper uses principal component analysis to condense the indicators of human well-being into four dimensions: income and consumption, means of production, means of subsistence, and resource acquisition ability, so as to measure human well-being. The analysis steps are [47]:

(1) Standardize raw data

$$
x_{i}=X_{i}-u_{i} / s_{i}
$$

where, $x_{i}$ is the standardized data, $X_{i}$ is the original data, $u_{i}$ is the mean value of the $i$ th index, and $s_{i}$ is the standard deviation of the $i$ th index.

(2) Calculate the correlation coefficient matrix

$$
R=\left[\begin{array}{cccc}
r_{11} & r_{12} & \Lambda & r_{1 p} \\
r_{21} & r_{22} & \Lambda & r_{2 p} \\
N & N & \Lambda & N \\
r_{p 1} & r_{p 2} & \Lambda & r_{p p}
\end{array}\right]
$$

where $r_{i j} i, j=1,2, \ldots, p$ is the correlation coefficient between the original variables $x_{i}$ and $x_{j}, r_{i j}=r_{j i}$, and its calculation formula is: 


$$
r_{i j}=\frac{\sum_{k=1}^{n}\left(x_{k i}-u_{i}\right)\left(x_{k j}-u_{j}\right)}{\sqrt{\sum_{k=1}^{n}\left(x_{k i}-u_{i}\right)^{2} \sum_{k=1}^{n}\left(x_{k j}-u_{j}\right)^{2}}}
$$

(3) Calculate eigenvalue and eigenvector

To some extent, eigenvalues can be regarded as indicators of the influence of principal components. To solve the characteristic equation $|\lambda I-R|=0$, the Jacobi method is often used to find the eigenvalues and arrange them in order of size

$$
\lambda_{1} \geq \lambda_{2} \geq \Lambda \geq \lambda_{p} \geq 0
$$

Then the eigenvectors corresponding to the eigenvalues are calculated respectively $e_{i}(i=1,2, \ldots p)$, require $\left\|e_{i}\right\|=1$, that is $\sum_{j=1}^{p} e_{i j}^{2}=1, e_{i j}$ represents the $j$ th component of vector $e_{i}$.

(4) Calculate contribution rate and cumulative contribution rate

$$
\begin{gathered}
a_{i}=\lambda_{i} / \sum_{k=1}^{p} \lambda_{k}, i=1,2, \ldots p \\
w_{i}=\sum_{k=1}^{i} \lambda_{k} / \sum_{k=1}^{p} \lambda_{k}, i=1,2, \ldots p
\end{gathered}
$$

Generally, the number of eigenvalues with a cumulative contribution rate of $85-95 \%$ is taken as the number of principal components.

(5) Calculate the comprehensive score of principal components

$$
F=a_{1} F_{1}+a_{2} F_{2}+\ldots \ldots+a_{m} F_{m}
$$

\subsection{Dynamic Panel Model}

Comparing the characteristics of data types, it is found that cross-sectional data mainly focuses on the behavior of microscopic individuals, while time-series data focuses on macroscopic comparisons. Panel data has two major advantages that cross-sectional and time-series data do not have, that is panel data can not only control the individual heterogeneity but also make a dynamic analysis. Using panel data for analysis can also effectively deal with various implicit variables $[48,49]$. In this paper, the lag of dependent variables is considered, that is, the current human well-being will be affected by the previous human well-being, so the previous human well-being should be taken as an explanatory variable, but because the explanatory variable is endogenous, it violates the assumption of strictly exogenous variables. Therefore, the dynamic panel data model is chosen, which can not only bring the first-order lag term of explanatory variables into the equation but also better deal with endogenous problems [50,51]. In the process of dynamic panel model analysis, the widely used OLS class estimators and ML class estimators have different degrees of bias and inconsistent estimators within groups. To solve this problem, Blundell and Bond proposed the consistent estimators of dynamic panel data models based on the generalized matrix method proposed by Hansen [52,53]. Considering that the dynamic panel model is:

$$
Y_{i t}=\sum_{j=1}^{p} \rho_{j} Y_{i t-j}+X_{i t} \beta+\delta_{i}+\varepsilon_{i t}
$$

Firstly, the equation is differentiated, and the individual effect is eliminated to get the equation as follows: 


$$
\Delta Y_{i t}=\sum_{j=1}^{p} \rho_{j} \Delta Y_{i t-j}+\Delta X_{i t} \beta+\Delta \varepsilon_{i t}
$$

The equation is estimated by GMM, and the basic GMM panel estimation rectangle formula is:

$$
g(\beta)=\sum_{i=1}^{M} g_{i}(\beta)=\sum_{i=1}^{M} Z_{i}^{\prime} \varepsilon_{i}(\beta),
$$

Here $Z_{i}$ is the $T_{i} \times p$ order instrumental variable matrix for each section $i$, and there are:

$$
\varepsilon_{i}(\beta)=\left(Y_{i}-f\left(X_{i t}, \beta\right)\right),
$$

In some cases, the sum is summed up in each period, so we will use the symmetric matrix to calculate. To estimate $\beta$, selecting a proper weighting matrix $\mathrm{H}$ of order, the least square formula of GMM estimation is:

$$
S(\beta)=\left(\sum_{i=1}^{M} Z_{i}^{\prime} \varepsilon_{i}(\beta)\right)^{\prime} H\left(\sum_{i=1}^{M} Z_{i}^{\prime} \varepsilon_{i}(\beta)\right)=g(\beta)^{\prime} H g(\beta),
$$

When the coefficient vector is known, the coefficient covariance matrix can be calculated:

$$
V(\beta)=\left(G^{\prime} H G\right)^{-1}\left(G^{\prime} H \wedge H G\right)\left(G^{\prime} H G\right)^{-1},
$$

Estimate by the following formula:

$$
\begin{gathered}
E\left(g_{i}(\beta) g_{i}(\beta)^{\prime}\right)=E\left(Z_{i}^{\prime} \varepsilon^{i}(\beta) \varepsilon^{i}(\beta)^{\prime} Z^{i}\right), \\
G(\beta)=\left\{-\sum_{i=1}^{M} Z_{i}^{\prime} \nabla f_{i}(\beta)\right\},
\end{gathered}
$$

In a simple linear model $f\left(X_{i t}, \beta\right)=X_{i t}^{\prime} \beta$, we can get the estimated value of the coefficient as follows:

$$
\hat{\beta}=\left\{\left(\sum_{i=1}^{M} Z_{i}^{\prime} X_{i}\right)^{\prime} H\left(\sum_{i=1}^{M} Z_{i}^{\prime} X_{i}\right)\right\}^{-1}\left\{\left(\sum_{i=1}^{M} Z_{i}^{\prime} X_{i}\right)^{\prime} H\left(\sum_{i=1}^{M} Z_{i}^{\prime} Y_{i}\right)\right\}=\left(M_{Z X}^{\prime} H M_{Z X}\right)^{-1}\left(M_{Z X}^{\prime} H M_{Z Y}\right)
$$

The variance is estimated as:

$$
V(\beta)=\left(M_{Z X}^{\prime} H M_{Z X}\right)^{-1}\left(M_{Z X}^{\prime} H \wedge H M_{Z X}\right)\left(M_{Z X}^{\prime} H M_{Z X}\right)^{-1},
$$

The general form of $M_{Z X}^{\prime}$ is:

$$
M_{Z X}=M^{-1}\left\{\sum_{i=1}^{M} A_{i}^{\prime} B_{i}\right\}
$$

\section{Results}

\subsection{Analysis of Energy Utilization and Economic Development in Qinghai-Tibet Plateau}

As shown in Figure 1a, the per capita GDP of Qinghai-Tibet Plateau increased year by year, reaching more than 10,000 yuan in 2006. After 2010, the per capita GDP grew more rapidly than before. This may be due to the government's increasing financial expenditure on Xinjiang, Qinghai, and other remote areas in western China, and its in-depth implementation of precise poverty alleviation policies, which have achieved remarkable results. From the perspective of provinces, the per capita GDP of Xinjiang, Qinghai, and Sichuan exceeded 40,000 yuan in 2017, among which Xinjiang has the highest per capita GDP. This may be because Xinjiang is rich in oil, coal and other resources, has a very big development space, and Xinjiang is located in the middle of Asia and Europe and is the province with 
the largest number of neighboring countries in China. Its superior geographical location and convenient transportation have greatly promoted Xinjiang's economic development, in addition, the implementation of counterpart aid policy has improved the overall quality of Xinjiang's economic development and entered the fast lane. Followed by the higher per capita GDP of Qinghai and Sichuan, the growth rate of per capita GDP of Yunnan and Tibet was slightly lower. Gansu is the province with the lowest per capita GDP in QinghaiTibet Plateau during the study period, and its per capita GDP is less than 30,000 yuan in 2017. This may be because the original industrial system of the petrochemical industry, nonferrous metallurgy, machinery, and electronics in Gansu Province developed well, but in recent years, due to the national environmental protection, many factories closed down, resulting in a further deadlock in its economic development. Moreover, Gansu's own infrastructure is backward and its industrial structure is unreasonable. Although it is rich in tourism resources, the development of tourism is not prominent due to inconvenient transportation and inadequate protection of tourist attractions, which makes the overall economic development slow.

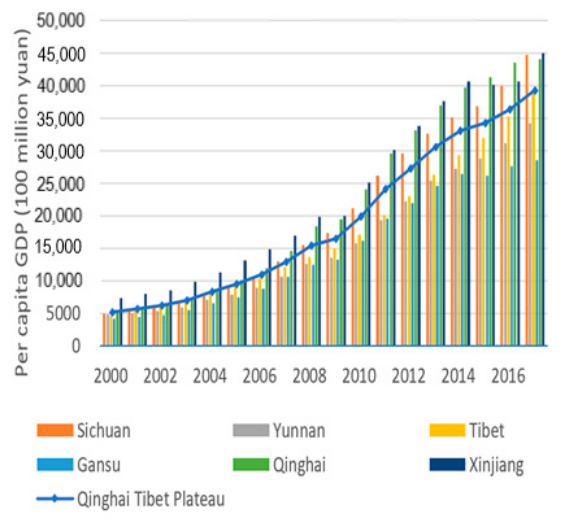

(a)

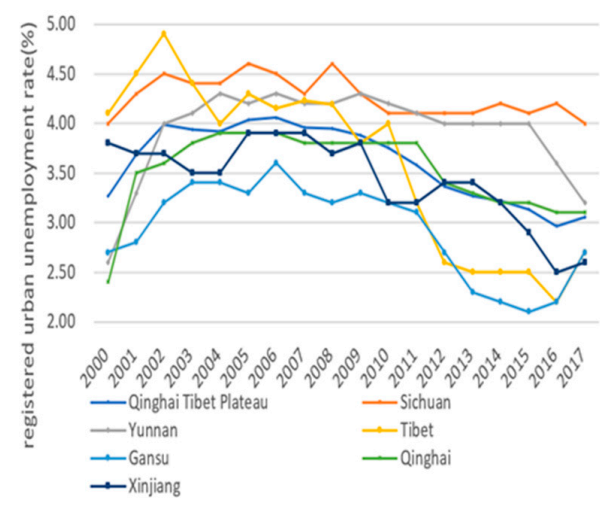

(b)

Figure 1. Change the trend of economic development indicators in Qinghai-Tibet Plateau. (a) Growth trend of Gross Domestic Product (GDP) per capita. (b) Trend of the urban registered unemployment rate.

It can be seen from Figure $1 \mathrm{~b}$ that the urban registered unemployment rate in the Qinghai-Tibet Plateau increased in the early stage of the study, but after 2007, it steadily fell below $4 \%$, and the average urban registered unemployment rate was $3.6 \%$. The changing trend of urban registered unemployment rates in Tibet and Gansu is similar to the overall change trend of the Qinghai-Tibet Plateau, which dropped to $2.6 \%$ and $2.7 \%$ respectively after 2012. During the study period, the registered urban unemployment rate in Sichuan and Yunnan was always high, reaching $4.26 \%$ and $3.92 \%$ on average. The urban registered unemployment rate in Qinghai and Xinjiang has changed little, basically around 3.5\%. The data show that the registered urban unemployment rate in Sichuan and Yunnan is relatively high, so some employment support measures should be taken in Sichuan and Yunnan. As far as the Qinghai-Tibet Plateau is concerned, both per capita GDP and employment level have been significantly improved, which also shows that the economy of Qinghai-Tibet Plateau has developed rapidly in the recent decade.

Figure 2a shows the change degree of energy consumption in Qinghai-Tibet Plateau from 2000 to 2017, in which energy consumption includes coke, gasoline, and natural gas consumption. Figure $2 \mathrm{~b}$ shows the changing trend of coke, gasoline, and natural gas consumption in Qinghai-Tibet Plateau. It can be seen from Figure 2a that the energy consumption of Qinghai-Tibet Plateau is generally on the rise, but it starts to decline after reaching its peak in 2013, which is consistent with the change of coke in Figure 2b, and the coke consumption still far exceeds other energy consumption, which indicates that coal is still the main energy consumption type in China. During the study period, the energy consumption of all provinces was basically on the rise. Only Yunnan began to decline in 2014, and Xinjiang began to decline in 2015. This may be because Yunnan and Xinjiang 
vigorously develop and utilize new energy sources such as wind, solar, and biomass energy, which have significantly improved the energy production structure. The energy consumption of Qinghai and Tibet is obviously less than that of other provinces, and the trend of change is slow, mainly because the geographical location of these two provinces has created their special climatic conditions and resource environment, and the inconvenient transportation has also caused their industries to be relatively weak, consuming less fossil energy, and the economic development mainly depends on agriculture and animal husbandry production. It can be seen from Figure $2 \mathrm{~b}$ that the gasoline consumption rate increased obviously after 2008, and the growth rate of gasoline consumption reached the highest in 2013. Compared with coke and gasoline, although the consumption of natural gas is less, its consumption is gradually increasing. This shows that although coal is still the main energy consumption in China, China has also achieved initial results in promoting the transformation of energy production mode.

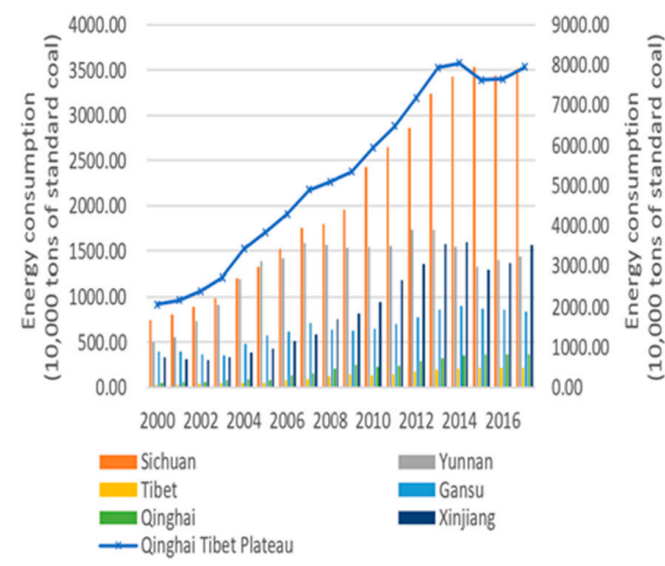

(a)

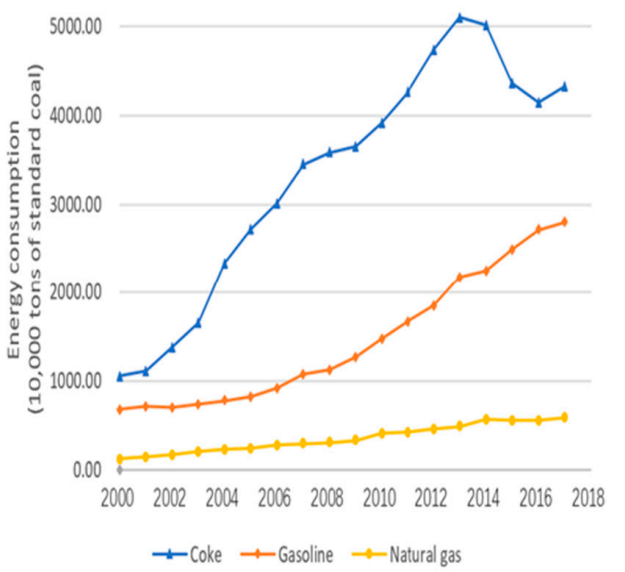

(b)

Figure 2. Change trend of energy utilization in Qinghai-Tibet Plateau. (a) Energy consumption in provinces. (b) Major categories of energy consumption.

\subsection{Principal Component Analysis}

Considering the complexity of human well-being, we measure human well-being from four dimensions: income and consumption, means of production, means of subsistence, and resource acquisition ability, and then analyze the impact of energy utilization and economic development on human well-being from each dimension. Since the analysis of energy utilization and economic development on each dimension of human well-being is an integral part of the overall analysis, the analysis of the impact of energy utilization and economic development on each dimension of human well-being is essential. Only in this way can we further analyze the impact of energy use and economic development on human well-being. According to the Formulas (1)-(7), we use stata software to extract and analyze the four dimensions of human well-being of income and consumption, means of production, means of subsistence, and resource acquisition ability. Kaiser-Meyer-Olkin $(\mathrm{KMO})$ is used to test the correlation between variables. Only when $\mathrm{KMO}$ is greater than 0.6 can principal component analysis be carried out. The higher KMO is, the stronger the linear relationship of variables is, and the more suitable principal component analysis is. In the principal component analysis, it is necessary to select principal components whose eigenvalues are greater than 1 , and the cumulative variance contribution rate is greater than $85 \%$, and then by rotating the load matrix, the corresponding eigenvectors can be obtained, and the selected principal components are calculated through the eigenvectors. In this way, the final comprehensive measurement result is obtained, and the information contained in each principal component is given an appropriate explanation. The specific analysis results are shown below. 


\subsubsection{Income and Consumption (IAC)}

From Table 2, the KMO test value is 0.6269 , which is basically considered suitable for principal component analysis. The cumulative variance contribution rate of the first three principal components reached $90.38 \%$, indicating that the first three principal components basically contain the information of all indicators, so we take the first three principal components to measure income and consumption well-being. The variance contribution rate of the first principal component is higher, which is $48.59 \%$, among which per capita disposable income of urban residents and rural residents have a larger characteristic positive value, while Engel coefficient of urban residents and rural residents has a larger characteristic negative vector value, which indicates that the first principal component mainly explains per capita disposable income and Engel coefficient of urban residents and rural residents. The variance contribution rate of the second principal component is $24.24 \%$, in which the proportion of tertiary industry and consumer price index have larger positive eigenvector values and negative eigenvector values respectively, indicating that the second principal component mainly explains the proportion of tertiary industry and consumer price index indicators. The variance contribution rate of the third principal component is $17.55 \%$. It can be seen that the consumer price index is mainly explained, and the interpretation distribution of other indicators is relatively uniform.

Table 2. Principal component analysis results of income and consumption.

\begin{tabular}{cccccccc}
\hline Variable & KMO & Comp1 & Comp2 & Comp3 & Comp4 & Comp5 & Comp6 \\
\hline PT & 0.4674 & 0.0662 & 0.7679 & 0.1455 & -0.5607 & 0.2621 & 0.0406 \\
PI & 0.2443 & 0.0208 & -0.4026 & 0.8297 & -0.1702 & 0.3458 & 0.0242 \\
UR & 0.6162 & 0.5236 & 0.2439 & 0.2236 & 0.3817 & -0.0483 & -0.6843 \\
RH & 0.6419 & 0.5523 & 0.1588 & 0.1142 & 0.3688 & 0.0088 & 0.7216 \\
UEC & 0.6175 & -0.4145 & 0.3031 & 0.4765 & 0.1763 & -0.6852 & 0.0934 \\
REC & 0.8229 & -0.4942 & 0.2676 & 0.0193 & 0.5864 & 0.5829 & 0.0095 \\
Eigenvalue & & 2.9153 & 1.4544 & 1.0530 & 0.28637 & 0.24967 & 0.04114 \\
Proportion (\%) & & 0.4859 & 0.2424 & 0.1755 & 0.0477 & 0.0416 & 0.0069 \\
Cumulative (\%) & & 0.4859 & 0.7283 & 0.9038 & 0.9515 & 0.9931 & 1 \\
Overall & 0.6269 & & & & & & \\
\hline
\end{tabular}

\subsubsection{Means of production (MOP)}

From Table 3, the KMO test value is 0.6289 , which is suitable for principal component analysis. The cumulative variance contribution rate of the first two principal components reached $86.1 \%$, indicating that most of the information of the original variables has been explained, so it is appropriate for us to take the first two principal components to measure the well-being of the means of production. It can also be seen from Table 3 that the variance contribution rate of the first principal component is $63.03 \%$, and its variables have large eigenvector values, which means that they have a high degree of correlation with the first principal component, and it also proves the first principal component is very important. The second principal component mainly explains the total power of agricultural machinery per unit area, indicating that the accumulation of two principal components can better express the information of the research problem.

Table 3. Principal component analysis results of means of production.

\begin{tabular}{ccccc}
\hline Variable & KMO & Comp1 & Comp2 & Comp3 \\
\hline CL & 0.5915 & 0.6240 & 0.1832 & 0.7597 \\
AM & 0.7192 & -0.5182 & 0.8246 & 0.2268 \\
AF & 0.6215 & 0.5849 & 0.5352 & -0.6095 \\
Eigenvalue & & 1.89081 & 0.692277 & 0.416913 \\
Proportion (\%) & & 0.6303 & 0.2308 & 0.139 \\
Cumulative (\%) & 0.6289 & 0.6303 & 0.861 & 1 \\
Overall & & & \\
\hline
\end{tabular}

\subsubsection{Means of Subsistence (MOS)}

From Table 4, the KMO test value is 0.6849 , which is suitable for principal component analysis. The cumulative variance contribution rate of the first two eigenvalues reached 
$85.28 \%$, and the data showed that the first principal component explained the per capita clothing expenditure of urban and rural residents and the per capita motorcycles ownership of rural residents, and the second principal component explained the per capita food possession and per capita motorcycle ownership of urban residents, which also proves that the first two principal components basically contain the information of all indicators. We take the first two principal components to measure the means of living.

Table 4. Principal component analysis results of means of subsistence.

\begin{tabular}{cccccccc}
\hline Variable & KMO & Comp1 & Comp2 & Comp3 & Comp4 & Comp5 & Comp6 \\
\hline GP & 0.6806 & 0.2867 & -0.4966 & -0.3551 & 0.7282 & 0.0782 & 0.0934 \\
CP & 0.5661 & 0.2234 & -0.0030 & 0.8964 & 0.3468 & 0.1254 & -0.1025 \\
UCE & 0.6904 & 0.5428 & 0.0279 & -0.1767 & -0.2375 & 0.4020 & -0.6748 \\
RCE & 0.7393 & 0.5482 & 0.0616 & 0.0163 & -0.2907 & 0.3013 & 0.7212 \\
RMC & 0.7885 & 0.5211 & 0.2343 & -0.0346 & 0.0333 & -0.8171 & -0.0606 \\
UMC & 0.2622 & -0.0336 & 0.8330 & -0.1940 & 0.4555 & 0.2411 & 0.0416 \\
Eigenvalue & & 3.69897 & 1.41778 & 0.367952 & 0.290986 & 0.125889 & 0.0984244 \\
Proportion (\%) & & 0.6165 & 0.2363 & 0.0613 & 0.0485 & 0.021 & 0.0164 \\
Cumulative (\%) & & 0.6165 & 0.8528 & 0.9141 & 0.9626 & 0.9836 & 1 \\
Overall & 0.6849 & & & & & &
\end{tabular}

\subsubsection{Resource Acquisition Ability (RAA)}

From Table 5, the KMO test value is 0.7805 , which is suitable for principal component analysis. The cumulative variance contribution rate of the first two principal components reached $90.19 \%$. The first principal component mainly explained the freight volume of civil aviation and the number of medical and health institutions, and the second principal component mainly explained the highway cargo turnover and passenger traffic. It shows that the first two principal components contain the information that all indicators have. We take the first two principal components to measure the resource acquisition ability.

Table 5. Principal component analysis results of resource acquisition ability.

\begin{tabular}{cccccc}
\hline Component & KMO & Comp1 & Comp2 & Comp3 & Comp4 \\
\hline CT & 0.8312 & 0.4211 & 0.8527 & 0.2718 & 0.1474 \\
PV & 0.8659 & 0.4909 & -0.4744 & 0.7307 & -0.0055 \\
CA & 0.7553 & 0.5334 & -0.2180 & -0.4951 & 0.6502 \\
MH & 0.7259 & 0.5451 & -0.0181 & -0.3836 & -0.7453 \\
Eigenvalue & & 2.99288 & 0.61482 & 0.262955 & 0.129348 \\
Proportion (\%) & & 0.7482 & 0.1537 & 0.0657 & 0.0323 \\
Cumulative (\%) & & 0.7482 & 0.9019 & 0.9677 & 1 \\
Overall & 0.7805 & & & & \\
\hline
\end{tabular}

The mean value of the results obtained by principal component analysis is 0 , and the positive and negative values in the comprehensive value are higher than and lower than the overall mean value respectively. It can be seen from Figure 3 that before 2010, the well-being of income and consumption, means of production, means of subsistence, and resource acquisition ability was less than its average value, indicating that the development level of Qinghai-Tibet Plateau was low in the first decade of the 20th century, and the regional development gap in China was obvious. After 2010, the well-being of income and consumption, means of production, means of subsistence, and resource acquisition ability gradually increased, which is roughly consistent with the changing trend of energy utilization and economic development in Qinghai-Tibet Plateau. This shows that energy utilization and economic development have promoted the improvement of human wellbeing to a certain extent. 


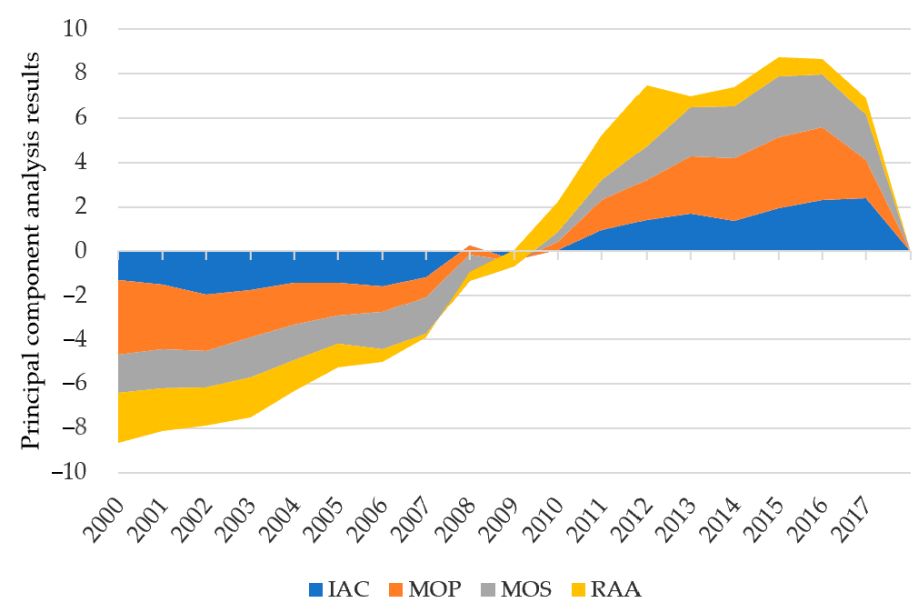

Figure 3. Principal component analysis results.

\subsection{Empirical Analysis of Dynamic Panel Model in Qinghai-Tibet Plateau}

This paper constructs a human well-being indicator system from four dimensions of income and consumption, means of production, means of subsistence, and resource acquisition ability. Based on the data of six provinces in Qinghai-Tibet Plateau from 2000 to 2017, this paper studies the impact of energy utilization and economic development on human well-being. Since the current human well-being is constrained and influenced by previous human well-being, a dynamic panel model is constructed. Due to the large magnitude gap between energy utilization, economic development, and human wellbeing data, in order to reduce data fluctuations and eliminate possible heteroscedasticity, logarithmic processing of independent variables is carried out. Then, the correlation test of energy utilization, economic development, and human well-being was carried out. As shown in Table 6, the correlation coefficients of energy utilization, economic development, and human well-being index data are relatively significant, indicating that there is a certain correlation between energy utilization, economic development, and human well-being. Most of the correlation coefficients between energy utilization and economic development indicators are relatively small, but there are also correlation coefficients between individual indicators greater than 0.8 , indicating that there may be multiple collinearity problems between energy utilization and economic development indicators. Therefore, we further calculated the variance inflation factor (VIF) of energy utilization and economic development indicators to finally determine whether there is a collinearity problem. Table 7 shows the results of the multicollinearity test, the VIF of each indicator is given in the table. The maximum VIF of $\ln$ Gasoline is 9.82, the minimum VIF of $\ln R U$ is 1.25 , and the average VIF of each indicator is 4.28 , which is less than the critical value of 10. It can be confirmed that there is no collinearity problem between the variables. Finally, the independent variable of human well-being in the previous period is introduced, and the dynamic panel model is used to analyze the impact of energy utilization and economic development on human well-being. The regression results are shown in Table 8.

Table 6. Variable correlation coefficient.

\begin{tabular}{|c|c|c|c|c|c|c|c|c|c|}
\hline & IAC & MOP & MOS & RAA & lnPGDP & $\ln R U$ & lnCoke & lnGasoline & lnNaturalgas \\
\hline IAC & 1 & & & & & & & & \\
\hline MOP & 0.108 & 1 & & & & & & & \\
\hline MOS & 0.143 & $0.725^{* * *}$ & 1 & & & & & & \\
\hline RAA & 0.173 * & $0.249^{* * *}$ & 0.128 & 1 & & & & & \\
\hline $\operatorname{lnPGDP}$ & $0.539^{* * *}$ & $0.515^{* * *}$ & $0.321^{* * *}$ & $0.246^{* *}$ & 1 & & & & \\
\hline $\ln R U$ & -0.089 & -0.482 *** & -0.148 & $0.317^{* *}$ & $-0.324 * *$ & 1 & & & \\
\hline lnCoke & $0.167 *$ & $0.489 * * *$ & $0.461^{* * *}$ & $0.593^{* * *}$ & $0.431^{* * *}$ & 0.035 & 1 & & \\
\hline lnGasoline & 0.106 & $0.506^{* * *}$ & $0.530 * * *$ & $0.685^{* * *}$ & $0.315^{* * *}$ & 0.096 & $0.872 * * *$ & 1 & \\
\hline lnNaturalgas & $0.269 * * *$ & $0.565^{* * *}$ & $0.445^{* * *}$ & $0.602 * * *$ & $0.556 * * *$ & 0.02 & $0.372 * * *$ & $0.443^{* * *}$ & 1 \\
\hline
\end{tabular}

Notes: ${ }^{*}, * *{ }^{* * *}$ represent the significance level of $10 \%, 5 \%$ and $1 \%$ respectively. 
Table 7. Multicollinearity test results.

\begin{tabular}{ccc}
\hline Variable & VIF & 1/VIF \\
\hline lnGasoline & 5.04 & 0.198381 \\
lnCoke & 4.96 & 0.201754 \\
lnPGDP & 1.81 & 0.475954 \\
$\operatorname{lnNaturalgas}$ & 1.23 & 0.551238 \\
$\operatorname{lnRU}$ & 1.23 & 0.813534 \\
\hline Mean VIF & & \\
\hline
\end{tabular}

Table 8. Effects of energy utilization and economic development on human well-being.

\begin{tabular}{|c|c|c|c|c|}
\hline & (1) & (2) & (3) & (4) \\
\hline & IAC & MOP & MOS & RAA \\
\hline L.IAC & $\begin{array}{c}0.359^{* * *} \\
{[0.086]}\end{array}$ & & & \\
\hline L.MOP & & $\begin{array}{c}0.737 * * * \\
{[0.114]}\end{array}$ & & \\
\hline L.MOS & & & $\begin{array}{c}0.881^{* * *} \\
{[0.037]}\end{array}$ & \\
\hline L.RAA & & & & $\begin{array}{c}0.520^{* * *} \\
{[0.128]}\end{array}$ \\
\hline lnPGDP & $\begin{array}{c}0.050 \\
{[0.052]}\end{array}$ & $\begin{array}{l}0.163 * \\
{[0.095]}\end{array}$ & $\begin{array}{c}0.196^{* * *} \\
{[0.073]}\end{array}$ & $\begin{array}{c}0.336^{* *} \\
{[0.162]}\end{array}$ \\
\hline $\ln R U$ & $\begin{array}{c}-0.413^{* * *} \\
{[0.116]}\end{array}$ & $\begin{array}{c}-0.449 * \\
{[0.234]}\end{array}$ & $\begin{array}{c}0.179 \\
{[0.144]}\end{array}$ & $\begin{array}{l}-0.100 \\
{[0.264]}\end{array}$ \\
\hline lnCoke & $\begin{array}{c}0.089 * * * \\
{[0.030]}\end{array}$ & $\begin{array}{c}0.004 \\
{[0.058]}\end{array}$ & $\begin{array}{c}0.036 \\
{[0.042]}\end{array}$ & $\begin{array}{c}0.015 \\
{[0.079]}\end{array}$ \\
\hline lnGasoline & $\begin{array}{l}0.105 * * \\
{[0.050]}\end{array}$ & $\begin{array}{c}-0.311^{* * *} \\
{[0.112]}\end{array}$ & $\begin{array}{l}-0.104 \\
{[0.067]}\end{array}$ & $\begin{array}{l}-0.255 \\
{[0.156]}\end{array}$ \\
\hline lnNaturalgas & $\begin{array}{l}-0.004 \\
{[0.041]} \\
\end{array}$ & $\begin{array}{c}0.118 \\
{[0.112]} \\
\end{array}$ & $\begin{array}{c}-0.098 * \\
{[0.059]}\end{array}$ & $\begin{array}{l}-0.047 \\
{[0.120]} \\
\end{array}$ \\
\hline $\operatorname{AR}(1)$ & 0.000 & 0.021 & 0.000 & 0.000 \\
\hline $\operatorname{AR}(2)$ & 0.119 & 0.487 & 0.781 & 0.729 \\
\hline Sargan test & 0.142 & 0.089 & 0.091 & 0.558 \\
\hline$N$ & 96 & 96 & 96 & 96 \\
\hline
\end{tabular}

Notes: ${ }^{* * *}, * * *$ represent the significance level of $10 \%, 5 \%$, and $1 \%$ respectively, and the value in [] is the standard error.

It can be seen from Table 8 that the adjoint probabilities $\mathrm{P}$ of the Sargan test are all greater than 0.05 , indicating that the instrumental variables are effective, and the model is robust. The adjoint probabilities of AR (1) in the serial correlation test are all less than 0.05 , indicating that the first-order sequence is correlated, and the adjoint probabilities of AR (2) are all greater than 0.05 , indicating that the second-order sequence is not correlated, and it has passed the serial correlation test. The models (1)-(4) in Table 8 are the results of using GMM to estimate and analyze the impact of energy utilization and economic development on human well-being from the four dimensions of income and consumption, means of production, means of subsistence, and resource acquisition ability. The regression results show that human well-being is a process of dynamic evolution, and the human well-being of the previous period has had a positive impact on the current human wellbeing. PGDP and coke have a positive impact on income and consumption, means of production, means of subsistence, and resource acquisition ability. that is, they promote the overall improvement of human well-being. PGDP and coke have a positive impact on income and consumption, means of production, means of subsistence, and the well-being of resource acquisition ability, that is, they promote the overall improvement of human well-being. Natural gas not only promotes the well-being of means of production, but also inhibits the well-being of income and consumption, means of subsistence, and resource 
acquisition ability. RU has a significant negative impact on the dimensions of income and consumption, means of production, and resource acquisition ability, and only has a positive impact on the well-being of means of subsistence. This means that the scale of unemployment has a greater inhibitory effect on human well-being than its promoting effect. Gasoline inhibits the improvement of the well-being of means of production, means of subsistence, and resource acquisition ability, but promotes the improvement of income and consumption well-being. The specific analysis of the impact of energy utilization and economic development on the well-being of income and consumption, means of production, means of subsistence, and resource acquisition ability is shown below.

\subsubsection{Influence of Energy Utilization and Economic Development on Income and Consumption Well-Being}

From an economic point of view, the level of residents' income affects the level of residents' consumption, which in turn stimulates the improvement of human well-being by promoting residents' consumption. It can be seen from Model (1) in Table 8 that PGDP, coke, and gasoline will significantly improve residents' income and consumption level, among which gasoline has the most significant impact on income and consumption, that is, for every $1 \%$ increase in gasoline consumption, income and consumption will increase by $0.105 \%$. This may be because coke, as the basic raw material in China, is widely used in various industries, especially in industrial industries. Its consumption promotes the rapid development of industry and promotes the improvement of GDP and residents' income. As gasoline is mainly used as a power fuel for transportation, the increase in its utilization means a sharp increase in the number of civilian cars, which also reflects the increase in residents' income and consumption well-being. Natural gas has a less obvious inhibitory effect on the improvement of income and consumption well-being, that is, for every $1 \%$ increase of natural gas consumption, income, and consumption decrease by $0.004 \%$. The main reason is that although the demand for natural gas is obviously increasing at present, the utilization of natural gas is highly dependent on the construction of long-distance pipeline network, while the long-distance trunk pipeline network in China has not covered the whole country, and provinces such as Tibet have not yet been connected to the national long-distance pipeline system, so the natural gas consumption still accounts for a small proportion of the total energy consumption, and it is mainly used in heating and chemical industries, and its impact on the income and consumption of human well-being is not significant. RU has a significant negative impact on income and consumption well-being. The data shows that for every $1 \%$ increase in RU, income, and consumption fall by $0.413 \%$. This also shows that the increase of unemployed people not only reduces the income level, but also leads to a decrease in social demand, which leads to insufficient consumption, which will inhibit production, and eventually create a social burden and reduce the overall level of human welfare.

\subsubsection{Influence of Energy Utilization and Economic Development on Means of Production Well-Being}

It can be seen from Table 8 that compared with Model (1) and Model (4), the previous means of production reflected by Model (2) has a more significant positive impact on the current means of production, mainly because the means of production are the resources or tools that workers need to use in production and the necessary material conditions for any society to carry out material production. Therefore, the technologies, tools, or resources needed in the current period are all improved on the basis of the previous period, and they are more dependent on the previous period. At the same time, it can be found that the coefficients of PGDP, coke, and natural gas are positive, indicating that the growth of PGDP and the consumption of coke and natural gas have brought about an improvement in the well-being of means of production. Among them, PGDP has the most significant influence on the means of production, that is, for every $1 \%$ increase of PGDP, the level of means of production will increase by $0.163 \%$. PGDP growth means that the country's western development strategy has achieved remarkable results. For example, the development of 
the 300,000-ton potash fertilizer project in Qinghai, the construction of the Qinghai-Tibet Railway, and the construction of the Zipingpu Water Control Project in Sichuan all indicate a substantial step in the western development. Significant progress has also been made in infrastructure construction as the foundation of Western Development, such as water conservancy construction, road, and railway construction, power grid and communications construction, etc. On this basis, the irrigation efficiency of cultivated land, the utilization degree of large-scale agricultural machinery, and the quality of agricultural chemicals have been gradually improved, which proves that the level of production materials has been significantly improved. In Model (2), for every 1\% increase in RU and gasoline utilization, the level of means of production will decrease by 0.449 and $0.311 \%$ respectively. This shows that RU and gasoline have a significant inhibitory effect on the means of production. The rise of RU will lead to the loss of part of the labor force, which leads to the decline of the utilization efficiency of the means of production. Considering the special geographical location of Qinghai-Tibet Plateau, we choose cultivated land, agricultural machinery, and agricultural chemistry to represent the means of production in this area. From the Model (1), it is known that gasoline utilization can significantly promote income and consumption well-being, and the improvement of income level may cause some rural population to flow to cities and towns, resulting in the reduction of farmers and herdsmen, which indirectly affects the reduction of production materials.

\subsubsection{Influence of Energy Utilization and Economic Development on Means of Subsistence Well-Being}

It can be seen from the Model (3) in Table 8 that the last period's means of subsistence had the most significant impact on the current period's means of subsistence. This is mainly due to the upward nature of human beings, which are superior to similar people and constantly improve themselves, and never give up the pursuit of a higher quality of life. The second is that for every $1 \%$ increase in PGDP, the level of means of subsistence increases by $0.196 \%$. This shows that the increase in PGDP has improved people's living standards, which is consistent with previous studies [54]. The utilization of coke has also promoted the improvement of the means of subsistence to a certain extent. This is mainly because the utilization of coke has promoted the development of industries that play a pivotal role in the national economy, and its effect indirectly reflects the changes in the level of residents' food, clothing, housing, and transportation. However, the use of gasoline and natural gas has inhibited the improvement of the means of subsistence to a certain extent. This may be because, although the West-East Gas Pipeline Project has improved means of production in the areas along the route to a certain extent, due to a large amount of household investment and engineering work in natural gas pipeline network facilities, most southwest regions are limited by resource endowment and technical conditions, and natural gas is difficult to promote economic growth. In addition, compared with traditional fossil energy sources such as coal and oil, natural gas has economic disadvantages. Under the national energy transformation strategy, the increase of natural gas utilization will lead to an increase in production costs and negative economic effects. However, unlike other models, RU promotes the well-being of the means of subsistence. This may be due to the unique terrain of Qinghai-Tibet Plateau, which is the main grassland animal husbandry production base in China. With the introduction of advanced animal husbandry production science and technology, the number of people who choose to return home to engage in animal husbandry has increased, and the opening of the Qinghai-Tibet Railway has promoted the development of local tourism and stimulated the economic growth of the region.

4.3.4. Influence of Energy Utilization and Economic Development on Resource Acquisition Ability Well-Being

From the model in Table 8 (4), it is known that for every $1 \%$ increase in PGDP, resource acquisition ability increases by $0.336 \%$, which shows that the increase in PGDP has actually given back to the residents. Coke utilization also promotes people's resource acquisition 
ability to a certain extent, which may be because coke utilization promotes economic development, which makes the government capable of providing better social security (such as employment, medical care) and social construction (such as building roads and airports), and makes it easier for residents to acquire resources. However, the utilization of gasoline and natural gas inhibits the improvement of resource acquisition ability to a certain extent, and the inhibition of gasoline utilization on the improvement of human welfare is more significant, that is, for every $1 \%$ increase in gasoline utilization, the resource acquisition ability decreases by $0.255 \%$. This may be because gasoline utilization is greater than natural gas utilization, and its impact is more significant than natural gas. Gasoline utilization has caused a certain amount of pollution to air quality, and the government has invested funds to control environmental pollution. In order to increase the urban penetration rate of natural gas, a low-carbon energy source, the government subsidizes the gas-using department with the state finance, which increases the fiscal expenditure, affects the government tax revenue, and indirectly limits the government's provision of other resources. Similarly, RU has a significant negative impact on the well-being of resource acquisition ability, because both the reduction of the total labor force and the increase of unemployed people will reduce the tax revenue in this region and hinder the construction of this region to some extent.

\subsection{Model Robustness Test}

Some important results have been obtained by analyzing the impact of energy utilization and economic development on human well-being. In order to verify the accuracy of these results, we use the fixed-effect model to test, and the robustness test results are shown in Table 9. Hausman test in the table shows that it is reasonable to use a fixed effect at a 5\% significance level. Comparing Table 8 with Table 9, we find that the regression coefficients of various forms are identical in sign, but there are differences in significance and numerical value. Therefore, it can be asserted that the previous correlation results are robust.

Table 9. Robustness test of the effects of energy utilization and economic development on human well-being.

\begin{tabular}{ccccc}
\hline & IAC & MOP & MOS & RAA \\
\hline $\ln$ PGDP & 0.0905 & $0.468^{* * *}$ & 0.385 & $0.492^{* *}$ \\
& {$[1.56]$} & {$[4.47]$} & {$[1.82]$} & {$[3.29]$} \\
$\operatorname{lnRU}$ & $-0.682^{* * *}$ & $-0.940^{* * *}$ & 0.388 & -0.157 \\
& {$[-7.64]$} & {$[-5.82]$} & {$[-1.19]$} & {$[0.68]$} \\
lnCoke & $0.113^{* * *}$ & 0.0462 & 0.0737 & 0.119 \\
& {$[3.67]$} & {$[-0.83]$} & {$[0.65]$} & {$[-1.50]$} \\
$\ln$ Gasoline & $0.181^{* * *}$ & $-0.190^{*}$ & -0.142 & -0.146 \\
& {$[3.47]$} & {$[-2.02]$} & {$[-0.75]$} & {$[-1.08]$} \\
$\ln$ Naturalgas & -0.0439 & 0.124 & -0.0522 & -0.0292 \\
& {$[-1.23]$} & {$[1.93]$} & {$[-0.40]$} & {$[0.32]$} \\
Hausman & 0.0000 & 0.0010 & 0.0163 & 0.0205 \\
$N$ & 96 & 96 & 96 & 96 \\
\hline
\end{tabular}

Notes: ${ }^{* * *},{ }^{* * *}$ represent the significance level of $10 \%, 5 \%$, and $1 \%$ respectively, and the value in [] is the standard
error.

4.5. Regression Analysis of the Impact of Energy Utilization and Economic Development on Human Well-Being in the Provinces of the Qinghai-Tibet Plateau

In order to further study the impact of energy utilization and economic development on human well-being in the provinces of Qinghai-Tibet Plateau, after testing the correlation and multicollinearity of energy utilization, economic development, and human well-being indicators, the regression analysis, and significance tests were carried out for each province. The results are shown below. 
4.5.1. Impact of Energy Utilization and Economic Development on Income and Consumption Well-Being in the Provinces of Qinghai-Tibet Plateau

Figure 4 shows the influence of energy utilization and economic development on the income and consumption well-being of each province. It can be seen from Figure 4 that the growth of PGDP promotes the growth of income and consumption in Sichuan, Xinjiang, Gansu, and Qinghai, but inhibits the improvement of income and consumption well-being in Yunnan and Tibet, which may be due to unreasonable industrial structure, lagging industrial development, slow development of emerging industries and hightech industries, and low circular efficiency of the economy in Tibet and Yunnan, which requires high-level knowledge workers to develop new technologies, improve efficiency and develop the economy. However, the decrease in the demand for ordinary workers leads to a decrease in their income, which in turn leads to a decline in market demand. RU only promoted Gansu's income and consumption level, but its promoting effect was relatively small. This may be because Gansu was in a period of great adjustment of the industrial structure during the study period, which caused a structural imbalance of labor market and wage rigidity, and formed a pattern of coexistence of unemployment and wage increase. Although RU showed a rising trend step by step, it remained within $4 \%$ after all, which had little impact on per capita income level, and could not become a driving force to restrain residents' income and consumption. From the energy utilization index, energy utilization has restrained the income and consumption level in Sichuan and promoted the income and consumption level in Yunnan. The utilization of coke and natural gas inhibited the increase of income and consumption in Xinjiang and Gansu, but the utilization of gasoline promoted the increase of income and consumption in Xinjiang and Gansu. Coke utilization promotes income and consumption in Qinghai and Tibet, but gasoline and natural gas utilization inhibit income and consumption well-being in Qinghai and Tibet, and gasoline utilization has no significant impact on income and consumption well-being in Tibet. This may be because, under the background of China's low-carbon economy and coal-based energy consumption mode, local governments have invested a lot of financial funds to vigorously develop clean technology and new energy development technology, which not only promotes economic growth but also increases environmental protection, thus affecting residents' work and income. However, due to the different levels of economic development in different places, there are certain differences in different places. For example, Sichuan has the best economic development in the Qinghai-Tibet Plateau, and its restrictions on the heavily polluted chemical industry will be higher, which will result in the closure of some chemical plants, the unemployment of skilled workers, and the decline of income and consumption levels. Yunnan mainly develops tobacco, mining, and tourism, so energy utilization will improve its income and consumption levels.

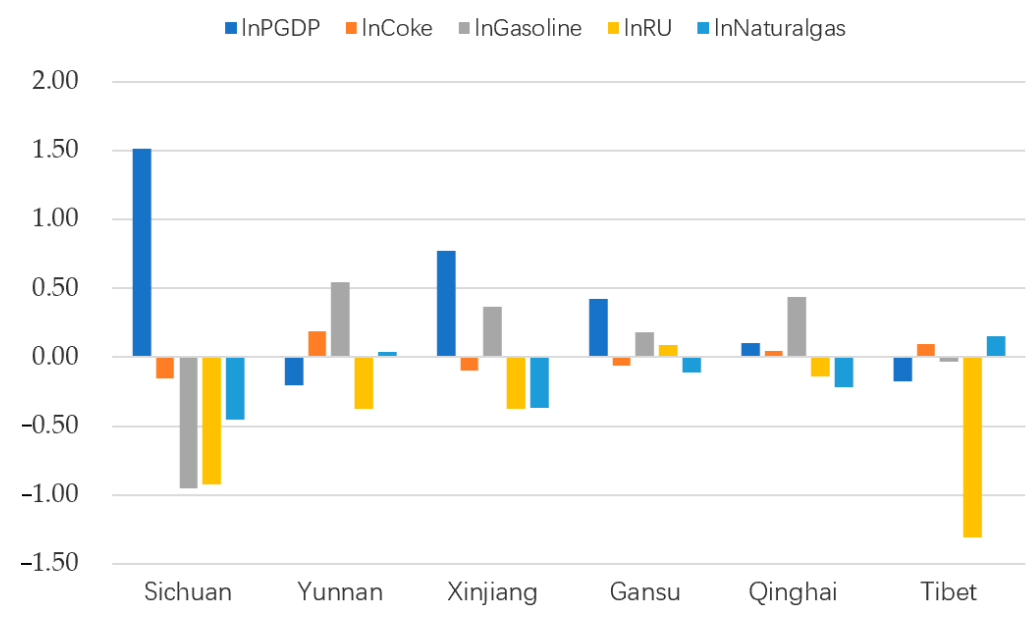

Figure 4. Influence of energy utilization and economic development on income and consumption well-being in each province. 
4.5.2. Impact of Energy Utilization and Economic Development on Well-Being Means of Production in the Provinces of Qinghai-Tibet Plateau

Figure 5 shows the impact of energy utilization and economic development on the well-being of the means of production in each province. In terms of economic development indicators, PGDP promoted the growth of means of production in Yunnan, Gansu, Qinghai, and Tibet, but inhibited the means of production in Sichuan and Xinjiang. RU inhibited the improvement of means of production in Sichuan, Gansu, and Qinghai, but promoted the means of production in Yunnan, Xinjiang, and Tibet obviously. This may be because the proportion of Sichuan's primary industry in GDP has dropped significantly during the study period, and the animal husbandry in the primary industry has increased and the planting industry has declined, that is, the demand for cultivated land, agricultural machinery, and chemistry has declined. Xinjiang's primary industry has a single structure and low management level. Agriculture, forestry, animal husbandry, and fishery have not given full play to their advantages and developed slowly or even stagnated. In addition, there is a big gap between the rich and the poor in Xinjiang. The economic development of resource-rich areas far exceeds that of agricultural development areas, and the growth of PGDP raises the price level. Therefore, for areas with weak agricultural foundation and slow development, the promotion of PGDP has degraded their existing wealth value. RU can promote the improvement of production materials in Yunnan, Xinjiang, and Tibet, which benefits from the development of tourism in the three provinces. From the perspective of energy utilization indicators, although natural gas has promoted the improvement of production materials in the six provinces, its promotion effect on Yunnan, Qinghai, and Tibet is not significant. Coke inhibited the improvement of means of production in most provinces, but its inhibitory effect on the well-being of Xinjiang's means of production was extremely insignificant. Gasoline has promoted the upgrading of means of production in most provinces. This may be because natural gas and gasoline are important heating and travel energy sources. The increase in their utilization means the improvement of residents' lives and production methods, and natural gas is also the best raw material for the manufacture of chemical fertilizers, driving the production and utilization of chemical fertilizers. Coke is mainly used in industrial production, and industrial development will reduce the proportion of agriculture in GDP, thereby reducing the level of means of production.

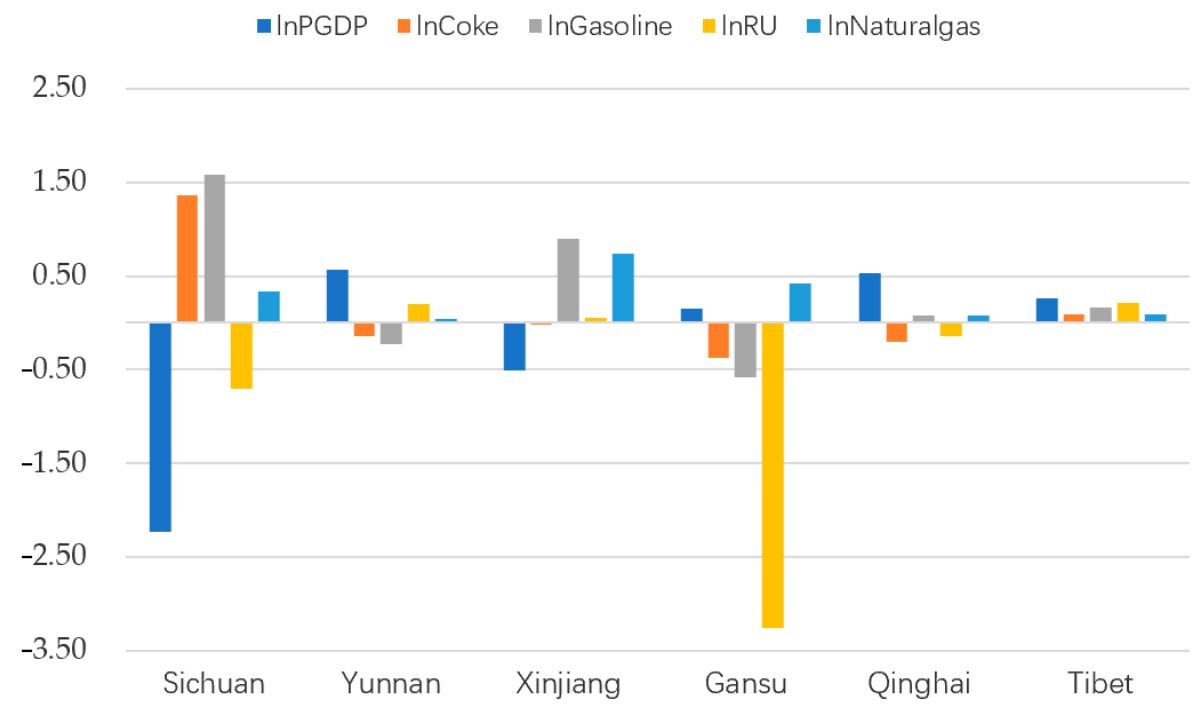

Figure 5. Influence of energy utilization and economic development on the well-being of means of production in each province. 
4.5.3. Impact of Energy Utilization and Economic Development on Well-Being of Means of Subsistence in the Provinces of Qinghai-Tibet Plateau

Figure 6 shows the influence of energy utilization and economic development on the well-being of the means of subsistence in each province. It can be seen that economic development and energy utilization have promoted the improvement of Tibet's means of subsistence. This shows that a series of special preferential policies for Tibet formulated by the central government and the implementation of measures to replace traditional energy with hydropower and solar energy resources in Tibet have made remarkable achievements in economic development and ecological construction in Tibet, and finally improved the living standards of residents. PGDP also promoted the improvement of means of subsistence in other provinces, especially in Sichuan and Xinjiang. Although RU inhibited the improvement of means of subsistence in Sichuan, Yunnan, and Gansu, it also promoted the level of means of subsistence in Xinjiang, Qinghai, and Tibet, and its promoting effect was greater than its inhibiting effect, which is the reason why RU promoted the improvement of means of subsistence in Qinghai-Tibet Plateau. Like the influence of energy utilization on means of production, coke inhibits the improvement of means of subsistence in most provinces, while gasoline promotes the improvement of means of subsistence in most provinces. The difference is that the utilization of natural gas promotes the improvement of means of subsistence in Yunnan, Gansu, and Tibet, but has a negative impact on the means of subsistence in Sichuan, Xinjiang, and Qinghai, which shows that the transformation of energy structure in Sichuan, Xinjiang, and Qinghai is more urgent than that in Yunnan, Gansu, and Tibet.

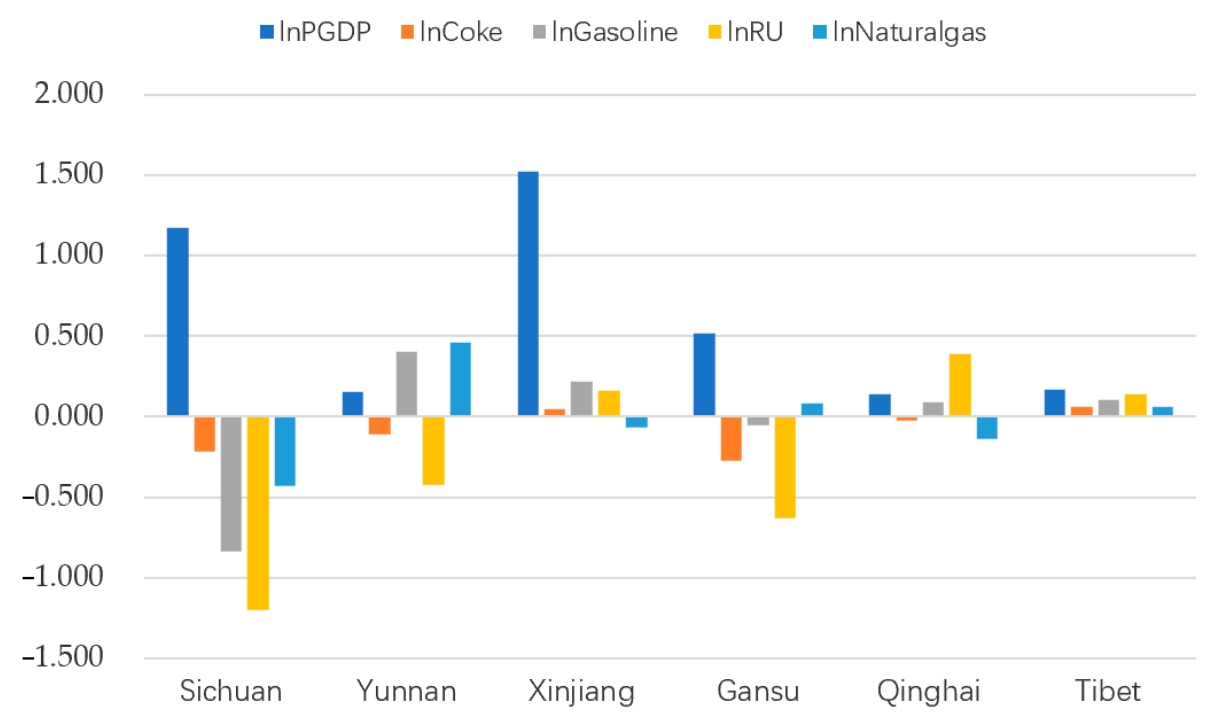

Figure 6. Influence of energy utilization and economic development on the well-being of means of subsistence in each province.

4.5.4. Impact of Energy Utilization and Economic Development on Resource Acquisition Ability Well-Being in the Provinces of Qinghai-Tibet Plateau

Figure 7 shows the influence of energy utilization and economic development on the well-being of the resource acquisition ability of each province. It can be seen from the figure that the impact of economic development and energy utilization on the resource acquisition ability of Xinjiang and Tibet is not significant. This may be because with the indepth implementation of the western development, although Xinjiang and Tibet pay more and more attention to infrastructure construction, their investment efficiency is relatively slow due to their relatively poor economic development foundation. The indicators in Figure 7 show that economic development obviously inhibits the improvement of Sichuan's resource acquisition ability, and energy utilization promotes the improvement of Sichuan's 
resource acquisition ability, but Gansu is just the opposite. This may be because road transportation, air freight transportation, and medical facilities all need energy consumption, which promotes the construction of social resources. However, Sichuan's economy is developing rapidly enough, and the government pays more attention to the quality of economic development and environmental protection while developing the economy. Part of the financial funds for infrastructure construction will be used for the development of energy-saving and emission-reduction technologies, so PGDP has a negative impact on Sichuan's resource acquisition. Obviously, PGDP has promoted the improvement of resource acquisition capabilities in Yunnan and Qinghai, and coke inhibited the improvement of resource acquisition ability. RU and natural gas have promoted the improvement of Yunnan's resource acquisition ability, gasoline consumption has inhibited the improvement of Yunnan's resource acquisition ability, and the influence of RU, natural gas, and gasoline on Qinghai's resource acquisition ability is the opposite of that of Yunnan. This may be because, under the background of vigorously developing tourism in Yunnan and Qinghai, the level of economic development has increased, the modes of travel have gradually diversified, and the passenger traffic and the business volume of transporting goods have also increased rapidly. The utilization of coke has promoted the industrialization process, and with the development of industrialization to a high level, miniaturized high-value industrial products, and consumer goods have been produced. The diversification of varieties and the improvement of transportation demand quality have led to the reduction of transportation demand for high-gravity goods in tons. Moreover, Yunnan Province mainly relies on China-Myanmar oil and gas pipelines to transport natural gas, while Qinghai mainly relies on local development and utilization. Different transportation routes and distances lead to different impacts of natural gas utilization on the resource acquisition ability well-being in the two provinces.

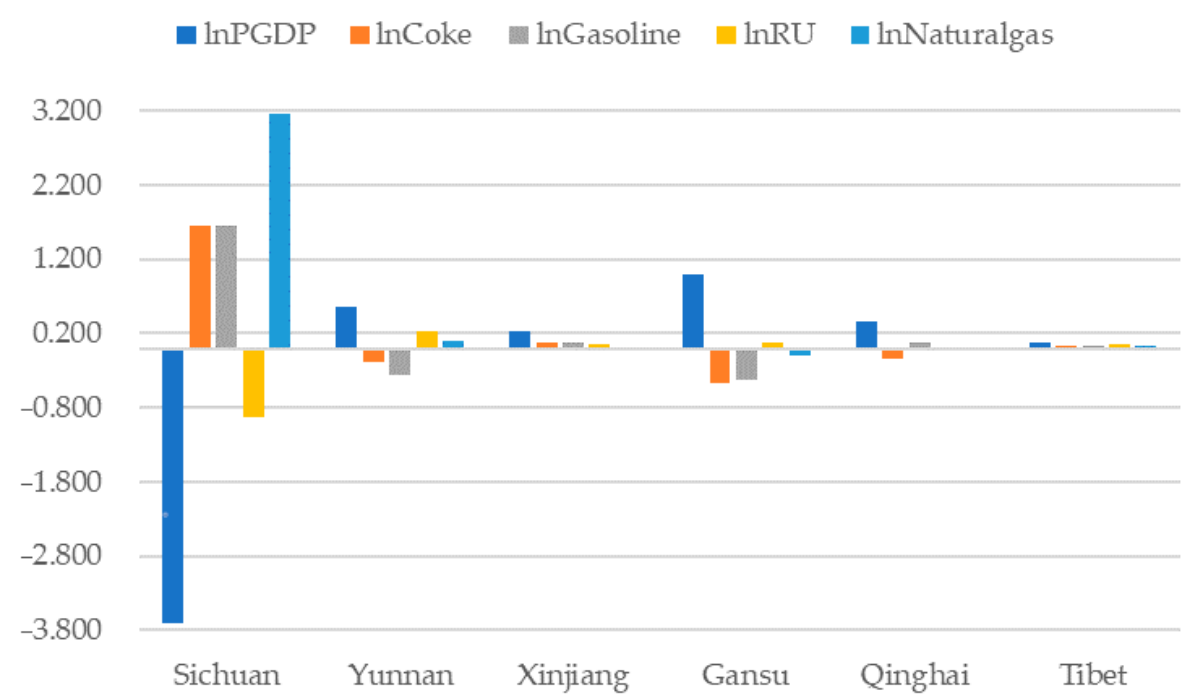

Figure 7. Influence of energy utilization and economic development on resource acquisition ability well-being in each province.

\section{Discussion}

5.1. Discussion on the Influence of Energy Utilization and Economic Development on Human Well-Being

The increase of PGDP has played a certain role in promoting the well-being of income and consumption, means of production, means of subsistence, and resource acquisition ability, which is consistent with the research results of Manuel et al. [9,10]. Moreover, this paper also concludes that PGDP has the most significant impact on the well-being of resource acquisition ability. This is because, with the development of the national economy, the central government and the whole country have given great support and special care to underdeveloped areas such as Qinghai-Tibet Plateau in terms of manpower, financial 
resources, material resources, and technology. For example, a series of policies such as implementing financial subsidies to Tibet and implementing differentiated tax policies to Qinghai have been promulgated, especially strengthening infrastructure construction in Qinghai-Tibet Plateau, vigorously supporting the construction of high-grade highways, railways, and airports, and forming a modern transportation network focusing on roads, aviation, railways, pipeline transportation, and communication, thus improving the regional development environment. Energy utilization does not have a positive impact on all aspects of human well-being, but coke significantly promotes all aspects of well-being. This shows that although Qinghai-Tibet Plateau is rich in natural resources, coal is still the main type of energy utilization. Therefore, the region should increase the proportion of non-fossil fuels through tax incentives and financial incentives, and promote the development and utilization of local renewable energy, such as solar energy, geothermal resources, and mineral resources. This is consistent with D'Adamo's research results [55]. At the same time, we encourage the transformation of the economic development mode, reduce the dependence of economic growth on energy consumption, and pay attention to the quality of economic development while improving the speed of economic development.

In the context of the Western Development Strategy, the economic development of the provinces in Qinghai-Tibet Plateau has been improved significantly, but there is still a phenomenon of uneven development within the region, that is, there are still large differences in the level of economic development among the provinces. For example, in 2017, Sichuan's GDP was more than 28 times that of Tibet, and Yunnan's GDP was 5.7 times that of Qinghai. Due to the different economic levels of different provinces, and considering the differences in storage resources and geographical environment, the human well-being level of different provinces is also very different. From the analysis results of provinces, it can be seen that the differences in the impact of energy utilization and economic development on human well-being are mainly caused by the differences in industrial structure and energy structure in each province. Therefore, the provincial governments should determine the development priorities according to their own situation, and adopt targeted policies and measures to improve the industrial structure and energy structure, such as reducing the proportion of industries mainly consuming fossil fuels, actively promoting the upgrading of the internal structure of the secondary industry and encouraging the development of the tertiary industry, and implementing different policies for different industries. Efforts will be made to improve the quality of economic development and the efficiency of energy utilization and to improve the well-being level of residents in the Qinghai-Tibet Plateau. Broadly speaking, it not only provides suggestions for building the Qinghai-Tibet Plateau into a unique model area for sustainable development of the plateau, but also provides experience and reference for regions with similar characteristics around the world, and makes great contributions to the realization of global sustainable development.

\subsection{Research Limitations and Future Prospects}

By studying the impact of energy utilization and economic development on human well-being in the Qinghai-Tibet Plateau region, this paper makes up for the lack of domestic research on the impact of energy utilization and economic development on human wellbeing in underdeveloped areas. However, there are still some deficiencies in the research process, which need to be improved in the future. First, the index system of human wellbeing needs to be improved. Based on the previous scholars' research and the characteristics of Qinghai-Tibet Plateau, considering the availability of data, the index system of human well-being only contains objective well-being but not subjective well-being. In addition, this paper only considers the impact of energy utilization and economic development on human well-being and does not conduct in-depth research on other influencing factors. Finally, this paper only analyzes the impact of energy utilization and economic development on human well-being from different dimensions but does not analyze the relationship between various dimensions. Therefore, in future research, we can consider the combination of objective well-being and subjective well-being to construct an index evaluation system 
of human well-being, and consider the impact of science and technology, urbanization, and cultural differences on human well-being. At the same time, human well-being in various dimensions may also have different degrees of connection. We should strengthen the research on the well-being relationship between different dimensions. In addition, in order to better achieve sustainable development, we should also strengthen the research on the relationship between sustainable development and resilience in the future.

\section{Conclusions}

Taking Qinghai-Tibet Plateau as the research object, this paper selects 18 indicators to measure human well-being and uses principal component analysis to condense each indicator into four dimensions: income and consumption means of production, means of subsistence, and resource acquisition ability. Then, the dynamic panel model is used to measure the impact of energy utilization and economic development on human well-being in all dimensions in the Qinghai-Tibet Plateau region as a whole and its provinces. The research shows that energy utilization and economic development have a certain promotion effect on human well-being, especially from 2010 to 2017. The specific research results are as follows:

(1) Influence of energy utilization and economic development on income and consumption well-being

PGDP, coke, gasoline, and natural gas all promote the income and consumption wellbeing of Qinghai-Tibet Plateau, but RU is the opposite. From the perspective of provinces, PGDP promoted the income and consumption well-being of Sichuan, Xinjiang, and Gansu, especially Sichuan, while RU only promoted the income and consumption of Gansu. The utilization of gasoline, coke, and natural gas only promote the improvement of Yunnan's income and consumption well-being, and it does not always have a positive impact on other provinces at the same time.

(2) Influence of energy utilization and economic development on the well-being of means of production

PGDP, coke, and natural gas promote the well-being of means of production in Qinghai-Tibet Plateau, but RU and gasoline have a reverse effect. From the perspective of provinces, the effects of various factors on Tibet are not significant. PGDP only inhibits the well-being of means of production in Sichuan and Xinjiang, while RU only significantly inhibits the well-being of the means of production in Sichuan and Gansu. Natural gas promotes the means of production in all provinces, Gasoline only significantly affects the well-being of means of production in Sichuan, Xinjiang, and Gansu, while coke only significantly affects the well-being of means of production in Sichuan and Gansu.

(3) Influence of energy utilization and economic development on the well-being of means of subsistence

PGDP, RU, and coke promote the well-being of means of subsistence in QinghaiTibet Plateau, but gasoline and natural gas have a reverse effect. From the perspective of provinces, PGDP has promoted the well-being of means of subsistence in all provinces, but its influence on Qinghai and Tibet is not significant, while RU can only promote Qinghai, Xinjiang, and Tibet. The utilization of gasoline, coke, and natural gas all promoted the improvement of Tibet's means of subsistence and inhibited the improvement of Sichuan's means of subsistence, but it did not always have a positive impact on the well-being of other provinces.

(4) Influence of energy utilization and economic development on resource acquisition ability well-being

PGDP and coke promote the well-being of resource acquisition ability in Qinghai-Tibet Plateau, but RU, gasoline, and natural gas have a reverse effect. From the perspective of provinces, energy utilization and economic development only have a significant impact on the well-being of Sichuan and Gansu, and economic development and energy utilization 
inhibit the well-being of Sichuan's resource acquisition ability but promote the well-being of Gansu's resource acquisition ability.

Author Contributions: Conceptualization, W.F. and H.W.; Data curation, M.M.; Formal analysis, M.M. and W.F.; Funding acquisition, H.W. and W.F.; Investigation, W.F. and M.M.; Methodology, W.F., M.M., X.D. and H.W.; Project administration, J.L. and X.D.; Supervision, J.L.; Visualization, W.F.; Writing—original draft, M.M.; Writing—review \& editing, W.F. and M.M. All authors have read and agreed to the published version of the manuscript.

Funding: This research was funded by the Second Tibetan Plateau Scientific Expedition and Research Program (2019QZKK0608), the Fundamental Research Funds for the Central Universities (2020MS128), Hebei Social Science Fund (HB20GL031) and National Natural Science Foundation of China (41901259).

Institutional Review Board Statement: Not applicable.

Informed Consent Statement: Not applicable.

Data Availability Statement: The data presented in this study are available on request from the corresponding author.

Conflicts of Interest: The authors declare no conflict of interest.

\section{References}

1. Summers, K.; Smith, L.M. The Role of Social and Intergenerational Equity in Making Changes in Human Well-Being Sustainable. Ambio 2014, 43, 718-728. [CrossRef] [PubMed]

2. Dietz, T.; Jorgenson, A.K. Towards a new view of sustainable development: Human well-being and environmental stress. Environ. Res. Lett. 2014, 9, 031001. [CrossRef]

3. Smith, L.M.; Case, J.L.; Smith, H.M.; Harwell, L.C.; Summers, J.K. Relating ecosystem services to domains of human well-being: Foundation for a U. S. index. Ecol. Indic. 2013, 28, 79-90. [CrossRef]

4. Wang, B.; Tang, H.; Xu, Y. Perceptions of human well-being across diverse respondents and landscapes in a mountain-basin system, China. Appl. Geogr. 2017, 85, 176-183. [CrossRef]

5. Zang, Z.; Zou, X.; Song, Q.; Li, Y.; Wang, T. Integrated sustainable development evaluation based on human well-being indices and pressure indices: A case study of the South China Sea Neighboring Countries. Soc. Sci. J. 2017, 54, 246-247. [CrossRef]

6. Zhan, S.G.; Wang, S.Y.; Fu, C. Literature review of well-being research. Guangxi Soc. Sci. 2014, 12, 100-105. (In Chinese)

7. Wei, H.; Liu, H.; Xu, Z.; Ren, J.; Lu, N.; Fan, W.; Zhang, P.; Dong, X. Linking ecosystem services supply, social demand and human well-being in a typical mountain-oasis-desert area, Xinjiang, China. Ecosyst. Serv. 2018, 31, 44-57. [CrossRef]

8. Yang, L.; Zhen, L.; Li, F.; Wei, Y.J.; Jiang, L.G.; Cao, X.C.; Long, X. Impacts of Ecosystem Services Change on Human Well-Being in the Loess Plateau. Resour. Sci. 2010, 32, 849-855. (In Chinese)

9. Rivera, M.A. The synergies between human development, economic growth, and tourism within a developing country: An empirical model for ecuador. J. Destin. Mark. Manag. 2017, 6, 221-232. [CrossRef]

10. Suri, T.; Boozer, M.A.; Ranis, G.; Stewart, F. Paths to Success: The Relationship Between Human Development and Economic Growth. World Dev. 2011, 39, 506-522. [CrossRef]

11. Pagliari, C.; Bucciarelli, E.; Alessi, M. Interdependence of world markets: Economic growth and social well-being. Procedia Comput. Sci. 2011, 3, 732-741. [CrossRef]

12. Zhang, Z.R.; Yuan, F.H.; Zhao, J.Z. Two Contrasts in China's Economic Development-A Survey Report on the Quality of Life in 30 Chinese Cities. Econ. Perspect. 2011, 7, 3-14. (In Chinese)

13. Hou, Y.; Zhou, S.; Burkhard, B.; Müller, F. Socioeconomic influences on biodiversity, ecosystem services and human well-being: A quantitative application of the DPSIR model in Jiangsu, China. Sci. Total. Environ. 2014, 490, 1012-1028. [CrossRef] [PubMed]

14. Brady, D.; Kaya, Y.; Beckfield, J. Reassessing the Effect of Economic Growth on Well-being in Less-developed Countries, 1980-2003. Stud. Comp. Int. Dev. 2007, 42, 1-35. [CrossRef]

15. Basakha, M.; Kamal, S.H.M. Industrial development and social welfare: A case study of Iran. Socio Econ. Plan. Sci. 2019, 68, 100661. [CrossRef]

16. Steinberger, J.K.; Roberts, J.T. From constraint to sufficiency: The decoupling of energy and carbon from human needs, 1975-2005. Ecol. Econ. 2010, 70, 425-433. [CrossRef]

17. Martínez, D.M.; Ebenhack, B.W. Understanding the role of energy consumption in human development through the use of saturation phenomena. Energy Policy 2008, 36, 1430-1435. [CrossRef]

18. Schandl, H.; West, J. Resource use and resource efficiency in the Asia-Pacific region. Glob. Environ. Chang. 2010, 20, 636-647. [CrossRef]

19. Yan, Y.; Wang, C.; Quan, Y.; Wu, G.; Zhao, J. Urban sustainable development efficiency towards the balance between nature and human well-being: Connotation, measurement, and assessment. J. Clean. Prod. 2018, 178, 67-75. [CrossRef] 
20. Hao, Y.; Liu, Y.; Weng, J.-H.; Gao, Y. Does the Environmental Kuznets Curve for coal consumption in China exist? New evidence from spatial econometric analysis. Energy 2016, 114, 1214-1223. [CrossRef]

21. Al-Mulali, U. Exploring the bi-directional long run relationship between energy consumption and life quality. Renew. Sustain. Energy Rev. 2016, 54, 824-837. [CrossRef]

22. Smyth, R.; Mishra, V.; Qian, X. The Environment and Well-Being in Urban China. Ecol. Econ. 2008, 68, 547-555. [CrossRef] [PubMed]

23. Ferreira, S.; Akay, A.; Brereton, F.; Cuñado, J.; Martinsson, P.; Moro, M.; Ningal, T.F. Life satisfaction and air quality in Europe. Ecol. Econ. 2013, 88, 1-10. [CrossRef]

24. Welsch, H. Environment and happiness: Valuation of air pollution using life satisfaction data. Ecol. Econ. 2006, 58, 801-813. [CrossRef]

25. Ferrer-I-Carbonell, A.; Gowdy, J.M. Environmental degradation and happiness. Ecol. Econ. 2007, 60, 509-516. [CrossRef]

26. Jorgenson, A.K.; Alekseyko, A.; Giedraitis, V. Energy consumption, human well-being and economic development in central and eastern European nations: A cautionary tale of sustainability. Energy Policy 2014, 66, 419-427. [CrossRef]

27. Jorgenson, A.K.; Dietz, T. Economic growth does not reduce the ecological intensity of human well-being. Sustain. Sci. 2015, 10, 149-156. [CrossRef]

28. Li, J.; Luo, Y.; Wang, S. Spatial effects of economic performance on the carbon intensity of human well-being: The environmental Kuznets curve in Chinese provinces. J. Clean. Prod. 2019, 233, 681-694. [CrossRef]

29. Wang, S.Y. Driving factors and spatiotemporal differentiation of human well-being change in China. Prog. Geogr. 2016, 35, 632-643. (In Chinese)

30. Sweidan, O.D.; Alwaked, A.A. Economic development and the energy intensity of human well-being: Evidence from the GCC countries. Renew. Sustain. Energy Rev. 2016, 55, 1363-1369. [CrossRef]

31. Knight, K.W.; Rosa, E.A. The environmental efficiency of well-being: A cross-national analysis. Soc. Sci. Res. 2011, 40, 931-949. [CrossRef]

32. Wang, Z.; Zhang, B.; Wang, B. Renewable energy consumption, economic growth and human development index in Pakistan: Evidence form simultaneous equation model. J. Clean. Prod. 2018, 184, 1081-1090. [CrossRef]

33. Millennium Ecosystem Assessment. Ecosystems and Human Well-Being: Synthesis; Island Press: Washington, DC, USA, 2005.

34. Jones, S.K.; Boundaogo, M.; Declerck, F.A.; Estrada-Carmona, N.; Mirumachi, N.; Mulligan, M. Insights into the importance of ecosystem services to human well-being in reservoir landscapes. Ecosyst. Serv. 2019, 39, 100987. [CrossRef]

35. Sarkki, S. Governance services: Co-producing human well-being with ecosystem services. Ecosyst. Serv. 2017, $27,82-91$. [CrossRef]

36. Fulford, R.S.; Smith, L.M.; Harwell, M.; Dantin, D.; Russell, M.; Harvey, J. Human well-being differs by community type: Toward reference points in a human well-being indicator useful for decision support. Ecol. Indic. 2015, 56, 194-204. [CrossRef]

37. Yang, L.Q.; Mei, L.; Guo, Y.H.; Jiang, H.Q. Comprehensive evaluation and temporal and spatial evolution of China's well-being level. Resour. Dev. Mark. 2018, 34, 355-360+417. (In Chinese)

38. National Bureau of Statistics (NBS). China Statistical Yearbook 2000-2018; China Statistics Press: Beijing, China, 2018.

39. Sichuan Bureau of Statistics. Sichuan Statistical Yearbook 2000-2018; China Statistics Press: Beijing, China, 2018.

40. Yunnan Bureau of Statistics. Yunnan Statistical Yearbook 2000-2018; China Statistics Press: Beijing, China, 2018.

41. Gansu Bureau of Statistics. Gansu Statistical Yearbook 2000-2018; China Statistics Press: Beijing, China, 2018.

42. Statistic Bureau of Xinjiang Uygur Autonomous Region. Xinjiang Statistical Yearbook 2000-2018; China Statistics Press: Beijing, China, 2018.

43. Qinghai Bureau of Statistics. Qinghai Statistical Yearbook 2000-2018; China Statistics Press: Beijing, China, 2018.

44. Bureau of statistics of Tibet Autonomous Region. Tibet Statistical Yearbook 2000-2018; China Statistics Press: Beijing, China, 2018.

45. National Energy Administration (NEA). China Energy Statistical Yearbook 2000-2018; China Statistics Press: Beijing, China, 2018.

46. Irwansyah, E.; Salim Pratama, E.; Ohyver, M. Clustering of Cardiovascular Disease Patients Using Data Mining Techniques with Principal Component Analysis and K-Medoids. Preprints 2020. [CrossRef]

47. Cheng, M.M.; Chen, W. Research on the Development of Marine Industry in Jiangsu Province Based on Principal Component Analysis. Stat. Manag. 2020, 35, 12-19. (In Chinese)

48. Debarsy, N.; Ertur, C.; Lesage, J.P. Interpreting dynamic space-time panel data models. Stat. Methodol. 2012, 9, 158-171. [CrossRef]

49. Wang, Z.G. Panel Data Model and Its Application in Economic Analysis; Economic Science Press: Beijing, China, 2008; 204p. (In Chinese)

50. Harris, M.N.; Mátyás, L. A Comparative Analysis of Different IV and GMM Estimators of Dynamic Panel Data Models. Int. Stat. Rev. 2007, 72, 397-408. [CrossRef]

51. Roodman, D. How to do Xtabond2: An Introduction to Difference and System GMM in Stata. Stata J. Promot. Commun. Stat. Stata 2009, 9, 86-136. [CrossRef]

52. Hansen, L.P. Large Sample Properties of Generalized Method of Moments Estimators. Econometrics 1982, 50, 1029. [CrossRef]

53. Blundell, R.; Bond, S. Initial conditions and moment restrictions in dynamic panel data models. J. Econ. 1998, 87, 115-143. [CrossRef] 
54. Bilan, Y.; Mishchuk, H.; Samoliuk, N.; Yurchyk, H. Impact of Income Distribution on Social and Economic Well-Being of the State. Sustainability 2020, 12, 429. [CrossRef]

55. D'Adamo, I.; Gastaldi, M.; Morone, P. The post COVID-19 green recovery in practice: Assessing the profitability of a policy proposal on residential photovoltaic plants. Energy Policy 2020, 147, 111910. [CrossRef] [PubMed] 